\title{
The maximum sloshing wave height evaluation in cylindrical metallic tanks by numerical means
}

\author{
Walid Samir Manser ${ }^{1}$, Mokhtar Touati ${ }^{1}$ and Rui CarneiroBarros ${ }^{2}$ \\ ${ }^{1}$ Faculty of Civil Engineering, USTHB University, Structural and Materials Department, 16111,Bab Ezzouare, Algiers \\ ${ }^{2}$ Faculty of Engineering, FEUP University, Civil Engineering Department, 4200-465, Porto, Portugal
}

\begin{abstract}
The metallic cylindrical storage tanks are very common structures in the field of civil engineering; These facilities are especially used in the industry in which they are used to store all kinds of products-which are for the most toxic or flammable. The tanks are also used in the storing of drinking water. When earthquakes, these structures must be strictly maintained in order to avoid that they lose their precious contents causing reactions that can cause more damage than the earthquake itself. In this study, the effects of the liquid height, the geometric parameters of tanks in the variation of the maximum sloshing wave height are studied: For this purpose, the software ANSYS V11.0 is used for modelling the tanks, the results found are compared with thus given in the Euro code 8
\end{abstract}

\section{Introduction}

Seismic events hitting Japan, the USA and Turkey have shown that the storage tanks are highly vulnerable to large seismic movements; failure modes such as: sliding, buckling of the walls and thero of damage (Figure 1) can lead to the outbreak of fire, that is why important parameters such as sloshing of fluid, basis upliftand the interaction: liquid-shell shall be considered in the dynamic analysis.

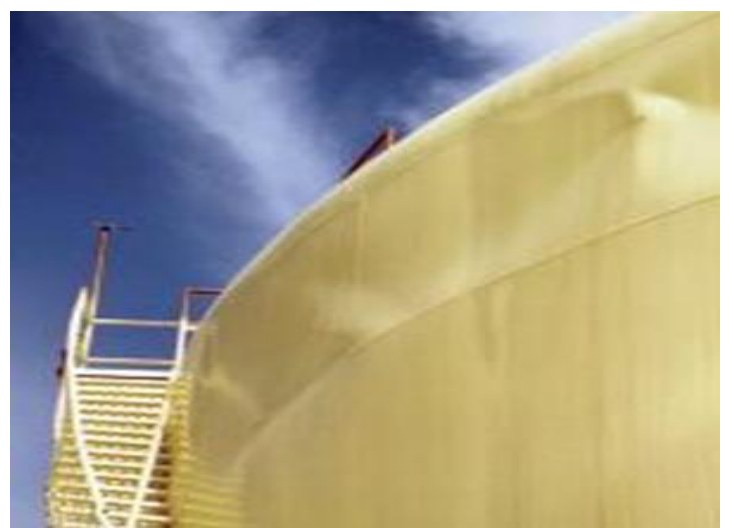

Figure 1. Damage on the roof of a tank after excessive sloshing liquid content.

The importance of LST seismic analysis is most seen their complex behaviour during vibration, a behaviour that has been proven during major earthquakes in areas containing tanks (Longbeach 1933, Chile 1960, Alaska 1964, Turkey1999, Japan 2011) where accidents occurs: the tanks containing flammable or toxic products are real bombs, and can sometimes cause more damages than the earthquake itself. During the Kocaeli earthquake in Turkey in1999, that hit the refinery Turpas $7^{\text {th }}$ European refinery-and caused more than US $\mathbf{\$ 5 0 0}$ millions of damages and losses. Duringthis earthquake, , covered tanks have suffered excessive sloshing and their roof rubbing with the walls and then created instantly sparks igniting the liquid. The fire then spread to crude oil tanks damaging 30to45 tanks covered by a roof (Figure 2).In addition to economic losses, large quantities of toxic material have been released in the environment. After every earthquake, the observations of damage to facilities are made in order assess the losses but also verify the validity of design standards, and improve them if necessary.

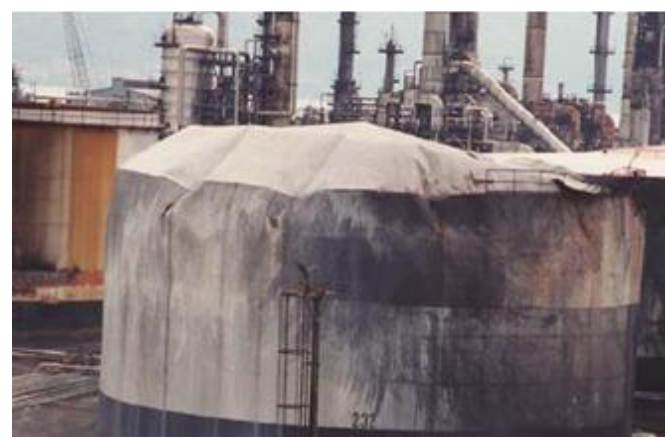

Figure 2. Activation of a fire in a tank in Turpas raffinery after Koaceli's Earthquake 1999 (Turkey). 


\section{Importance of sloshing and the MSWH (maximum sloshing wave height)}

The sloshing phenomenon is the oscillation of the liquid surface due to excitation of the container. In fact, during an earthquake, the fluid in a tank oscillates with a rather special way: The upper part move with large periods of time, this part is usually called: the convective part. While the rest of the liquid (the lower part) called the impulsive part has a similar movement to the rigid shell of the tank (Figure 3).

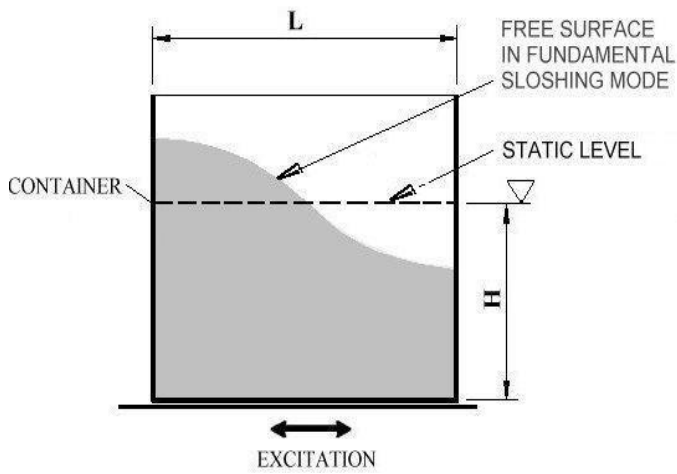

Figure 3. Schematic presentation of the sloshing.

Since the vertical movement of the convective fluid can lead to the loss of the liquid contained in the tank oralthough a damage in the tank's roof, the sloshing height must be held into account during the design and calculation of tanks.

\section{The sloshing according to standards}

The most important aspect for the tanks is the sloshing behaviour and the dynamic response of the tanks under seismic excitation.

Sloshing waves with large amplitudes cause damage to the roofs of the tanks and make them temporarily unusable, therefore, the liquid in this area can cause fires. To avoid such disasters, the sloshing of the liquid in the tanks must be considered to determine the minimum "Free-Board" required .The "Free- Board" is given by the expressions available in the various regulations covering the tanks:

\section{$\underline{\mathbf{E C 8}}$}

$$
d_{\max }=0,84 R S_{e}\left(T_{c 1}\right)
$$

where: $(\mathrm{Tc} 1)$ is the appropriate elastic spectrum of the acceleration in $\mathrm{g}$.

When an impulsive acceleration act son a liquid, this can produce a pressure significant hydrodynamic pressures produced by the free surface on the tank walls, the estimation methods of these impacts and the hydrodynamic pressures are not yet well developed and are often determined by the experimental means.

The tank diameter (D), the height(H)and the liquid level(HL)are the dominant factors for evaluating the sloshing of the fluid.

\section{Purpose of the study}

Given the importance of sloshing in the seismic response of metallic cylindrical tanks to an excitation, the study of the evolution of the maximum sloshing height according to various parameters such as the geometric properties of the tank is done. For this purpose, 45 tanks constrained at the base with different ratios $(\mathrm{H} / \mathrm{R})$ were treated with dynamic on- linear analyzes, these tanks are simulated in ANSYS v11.0 Software program using the finite element method for 3Dmodelling of the fluid-shell system. Material properties were assumed homogeneous. The shell has been modelled by SHELL63 elements and the fluid contained in the tank is modelled by FLUID 80elements. The results are then compared with the values prescribed in EUROCODE8.

For the analysis, a recording of Tabas earthquake with PGA 0,328g was used, only excitation in the horizontal direction UX has been taken into account in the time-history analysis to study the variation of the MSWH's values during the earthquake (see Fig. 4, 5).

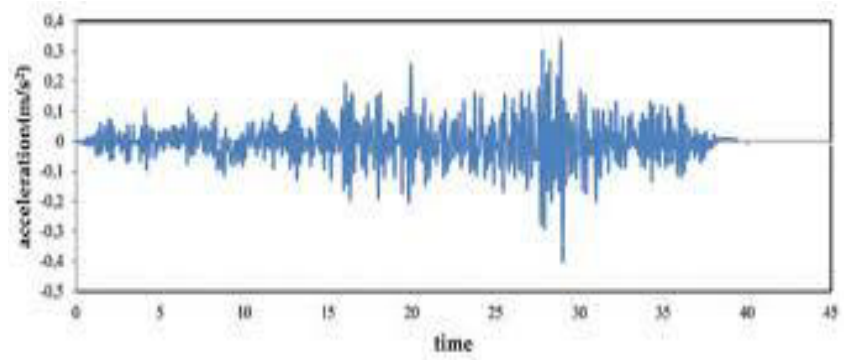

Figure 4. Horizontal component of the recording of Tabas's Earthquake.

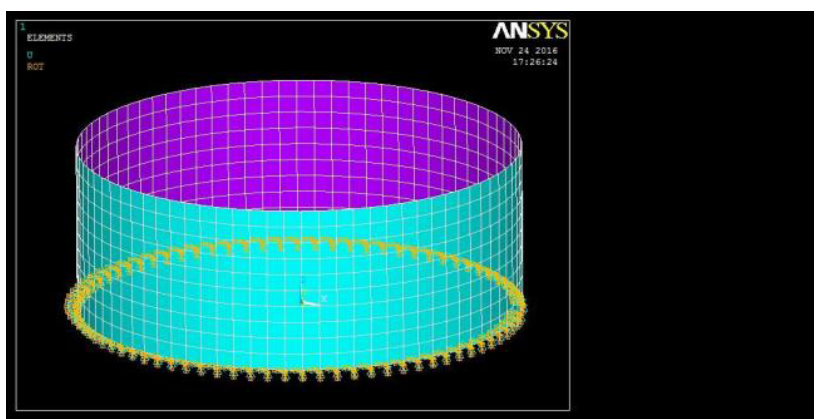

Figure 5. Modeling of the liquid-shell system in 3D by ANSYS Software.

\section{Specifaication of the studied tanks}

$$
T_{d}=\frac{4,9 D(H l-0,3) G}{S d}+C A
$$




$$
T_{t}=\frac{4,9 D(H l-0,3)}{S t}
$$

Where:

D: Tank diameter.

$\mathrm{H}_{1}$ : The liquid's height

$\mathrm{G}$ : the specific density of the liquid content.

$\mathrm{CA}$ : the corrosion factor.

$\mathrm{S}_{\mathrm{d}}$ : The allowable stress for calculation conditions in $\mathrm{MPa}$.

$\mathrm{S}_{\mathrm{t}}$ : The allowable stress for the hydrostatic test in MPa.

The results obtained are summarized in the following tables:

Table 1. Tanks's dimensions of the 1st Part.

\begin{tabular}{|c|c|c|c|c|c|}
\hline \multicolumn{7}{|c|}{ Part I } \\
\hline $\mathrm{n}$ & $\begin{array}{c}\text { Tank } \\
\text { height } \\
\mathrm{H}(\mathrm{m})\end{array}$ & $\begin{array}{c}\text { Liquid } \\
\text { height } \\
\mathrm{H}_{1}(\mathrm{~m})\end{array}$ & $\begin{array}{c}\text { Tank } \\
\text { radius } \\
\mathrm{R}(\mathrm{m})\end{array}$ & $\begin{array}{c}\text { Thikness t } \\
(\mathrm{mm})\end{array}$ & $\begin{array}{c}\text { Thikness } \\
\text { adopted } \\
\mathrm{t}_{\text {adop }}(\mathrm{mm})\end{array}$ \\
\hline 1 & 5 & 2,5 & 10 & 1,58 & 10 \\
\hline 2 & 6 & 3 & 10 & 1,93 & 10 \\
\hline 3 & 7 & 3,5 & 10 & 2,29 & 10 \\
\hline 4 & 8 & 4 & 10 & 2,65 & 10 \\
\hline 5 & 9 & 4,5 & 10 & 3 & 10 \\
\hline 6 & 10 & 5 & 10 & 3,36 & 10 \\
\hline 7 & 11 & 5,5 & 10 & 3,72 & 10 \\
\hline 8 & 12 & 6 & 10 & 4,08 & 10 \\
\hline 9 & 13 & 6,5 & 10 & 4,44 & 10 \\
\hline 10 & 14 & 7 & 10 & 4,8 & 10 \\
\hline 11 & 15 & 7,5 & 10 & 5,16 & 10 \\
\hline 12 & 16 & 8 & 10 & 5,52 & 10 \\
\hline 13 & 17 & 8,5 & 10 & 5,88 & 10 \\
\hline 14 & 18 & 9 & 10 & 6,24 & 10 \\
\hline 15 & 19 & 9,5 & 10 & 6,6 & 10 \\
\hline
\end{tabular}

Table 2. Tanks's dimensions of the 2nd Part

\begin{tabular}{|c|c|c|c|c|c|}
\hline \multicolumn{5}{|c|}{ Part II } \\
\hline $\mathrm{n}$ & Tank & Liquid & Tank & Thikness t & Thikness \\
\hline
\end{tabular}

\begin{tabular}{|c|c|c|c|c|c|}
\hline & $\begin{array}{c}\text { height } \\
\mathrm{H}(\mathrm{m})\end{array}$ & $\begin{array}{c}\text { height } \\
\mathrm{H}_{1}(\mathrm{~m})\end{array}$ & $\begin{array}{c}\text { radius } \\
\mathrm{R}(\mathrm{m})\end{array}$ & $(\mathrm{mm})$ & $\begin{array}{c}\text { adopted } \\
\mathrm{t}_{\text {adop }}(\mathrm{mm})\end{array}$ \\
\hline 16 & 20 & 12 & 10 & 8,36 & 30 \\
\hline 17 & 20 & 12 & 12 & 10,04 & 30 \\
\hline 18 & 20 & 12 & 14 & 11,72 & 30 \\
\hline 19 & 20 & 12 & 16 & 13,39 & 30 \\
\hline 20 & 20 & 12 & 18 & 15,07 & 30 \\
\hline 21 & 20 & 12 & 20 & 16,74 & 30 \\
\hline 22 & 20 & 12 & 22 & 18,41 & 30 \\
\hline 23 & 20 & 12 & 24 & 20,09 & 30 \\
\hline 24 & 20 & 12 & 26 & 21,76 & 30 \\
\hline 25 & 20 & 12 & 28 & 23,44 & 30 \\
\hline 26 & 20 & 12 & 30 & 25,11 & 30 \\
\hline 27 & 20 & 12 & 32 & 26,78 & 30 \\
\hline 28 & 20 & 12 & 34 & 28,46 & 30 \\
\hline 29 & 20 & 12 & 36 & 30,13 & 30 \\
\hline 30 & 20 & 12 & 38 & 31,81 & 30 \\
\hline
\end{tabular}

Table 3. Tanks's dimensions of the 3rd Part.

\begin{tabular}{|c|c|c|c|c|c|}
\hline \multicolumn{7}{|c|}{ Part III } \\
\hline $\mathrm{n}$ & $\begin{array}{c}\text { Tank } \\
\text { height } \\
\mathrm{H}(\mathrm{m})\end{array}$ & $\begin{array}{c}\text { Liquid } \\
\text { height } \\
\mathrm{H}_{1}(\mathrm{~m})\end{array}$ & $\begin{array}{c}\text { Tank } \\
\text { radius } \\
\mathrm{R}(\mathrm{m})\end{array}$ & $\begin{array}{c}\text { Thikness } \mathrm{t} \\
(\mathrm{mm})\end{array}$ & $\begin{array}{c}\text { Thikness } \\
\text { adopted } \\
\mathrm{t}_{\text {adop }}(\mathrm{mm})\end{array}$ \\
\hline 31 & 10 & 2,5 & 10 & 1,57 & 10 \\
\hline 32 & 10 & 3 & 10 & 1,93 & 10 \\
\hline 33 & 10 & 3,5 & 10 & 2,29 & 10 \\
\hline 34 & 10 & 4 & 10 & 2,65 & 10 \\
\hline 35 & 10 & 4,5 & 10 & 3 & 10 \\
\hline 36 & 10 & 5 & 10 & 3,36 & 10 \\
\hline 37 & 10 & 5,5 & 10 & 3,72 & 10 \\
\hline 38 & 10 & 6 & 10 & 4,08 & 10 \\
\hline 39 & 10 & 6,5 & 10 & 4,44 & 10 \\
\hline 40 & 10 & 7 & 10 & 4,8 & 10 \\
\hline 41 & 10 & 7,5 & 10 & 5,16 & 10 \\
\hline 42 & 10 & 8 & 10 & 5,52 & 10 \\
\hline 43 & 10 & 8,5 & 10 & 5,88 & 10 \\
\hline 44 & 10 & 9 & 10 & 6,24 & 10 \\
\hline 45 & 10 & 9,5 & 10 & 6,6 & 10 \\
\hline
\end{tabular}

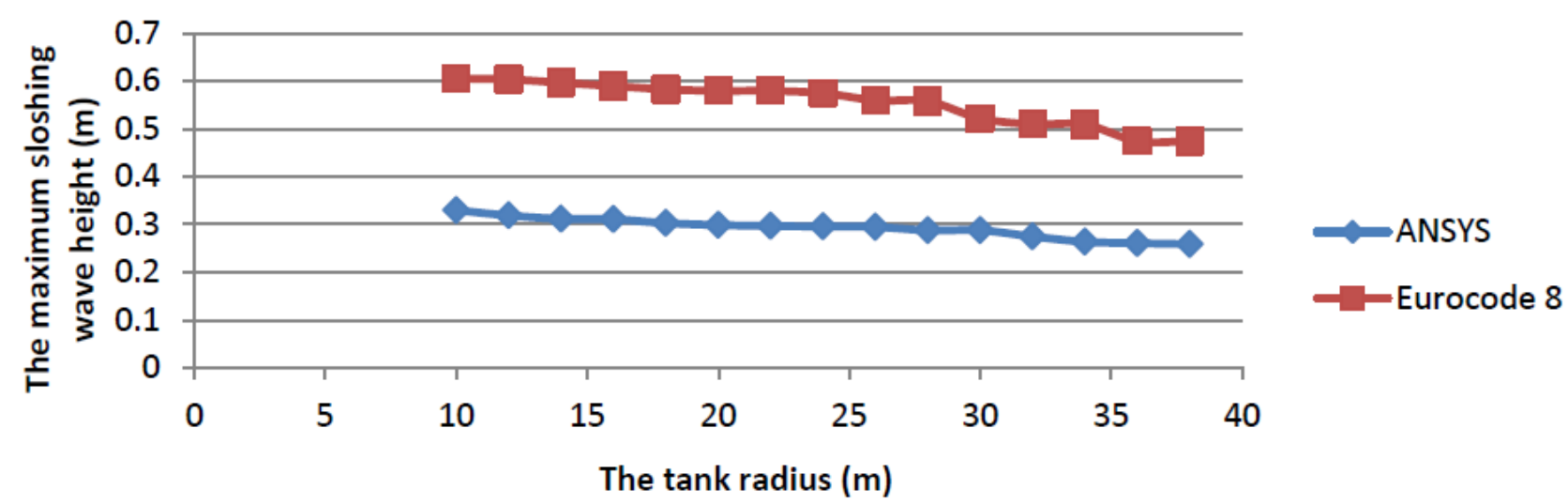

Figure 6. The MSWH's evolution versus the tank Height.

Generally, there are two methods to design the thickness of the tank shell plates: The first one is called "the variable-design point method that is mainly used in tanks with radius higher than $60 \mathrm{~m}$, while the second method - used in our case - is used for tanks with small diameters, it is called "the 1 foot method". In the latter method, the minimum thickness to be used is the greater of the two following values [3] (see Fig. 6-Fig. 8). 


\section{Numerical analysis}

To study the effects of different parameters on the MSWH, the tanks are analyzed under the following conditions:

1.Tanks with height's variation only (Part I) .

2.Tanks with radius variation only (Part II).

3.Tanks with variation in the liquid's heights (Part III).

\subsection{Tanks with variation in height only}

In this case, the tanks have a constant radius of $10 \mathrm{~m}$ while the changing their heights. The dimensions of each tank and the results are summarized in the table below:

Table 4. Results for the 1st Part.

\begin{tabular}{|c|c|c|c|}
\hline \multicolumn{5}{|c|}{ Part I } \\
\hline $\mathrm{n}$ & $\mathrm{H}(\mathrm{m})$ & $\begin{array}{c}\text { MSWH } \\
\text { ANSYS }(\mathrm{m})\end{array}$ & $\begin{array}{c}\text { MSWH EC8 } \\
(\mathrm{m})\end{array}$ \\
\hline 1 & 5 & 0,247 & 0,63 \\
\hline 2 & 6 & 0,252 & 0,63 \\
\hline 3 & 7 & 0,254 & 0,672 \\
\hline 4 & 8 & 0,266 & 0,714 \\
\hline 5 & 9 & 0,274 & 0,756 \\
\hline 6 & 10 & 0,294 & 0,808 \\
\hline 7 & 11 & 0,305 & 0,839 \\
\hline 8 & 12 & 0,308 & 0,86 \\
\hline 9 & 13 & 0,32 & 0,845 \\
\hline 10 & 14 & 0,313 & 0,84 \\
\hline 11 & 15 & 0,308 & 0,814 \\
\hline 12 & 16 & 0,303 & 0,809 \\
\hline 13 & 17 & 0,293 & 0,804 \\
\hline 14 & 18 & 0,288 & 0,798 \\
\hline 15 & 19 & 0,278 & 0,798 \\
\hline
\end{tabular}

\subsection{Tanks with variation in radius only:}

At present, we are interested on the effect of the radius on the MSWH. For this purpose, we studied the variation of the MSWH depending different radius. The height of the tanks being set $20 \mathrm{~m}$.

Table 5. Results of the 2nd Part.

\begin{tabular}{|c|c|c|c|}
\hline \multicolumn{4}{|c|}{ Part II } \\
\hline $\mathrm{n}$ & $\mathrm{R}(\mathrm{m})$ & $\begin{array}{c}\text { MSWH } \\
\text { ANSYS }(\mathrm{m})\end{array}$ & $\begin{array}{c}\text { MSWH EC8 } \\
(\mathrm{m})\end{array}$ \\
\hline 16 & 10 & 0,33 & 0,606 \\
\hline 17 & 12 & 0,319 & 0,604 \\
\hline 18 & 14 & 0,312 & 0,597 \\
\hline 19 & 16 & 0,311 & 0,59 \\
\hline
\end{tabular}

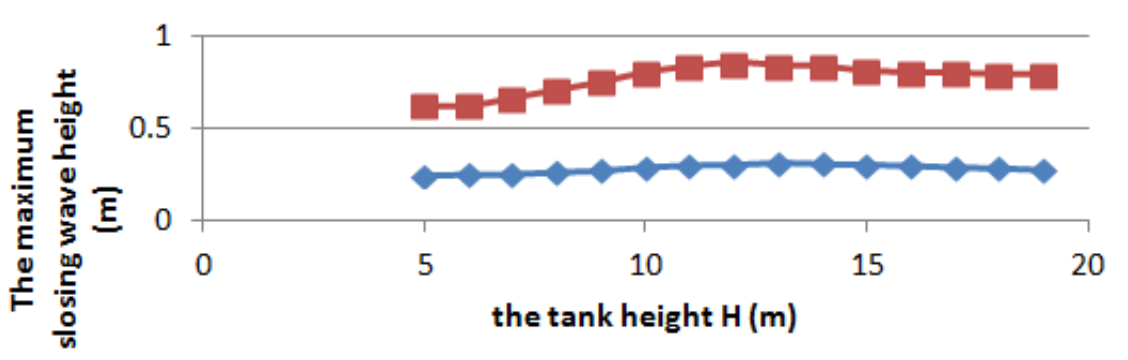

Figure 7. The MSWH's evolution versus the tank radius.

\begin{tabular}{|c|c|c|c|}
\hline 20 & 18 & 0,303 & 0,583 \\
\hline 21 & 20 & 0,299 & 0,58 \\
\hline 22 & 22 & 0,297 & 0,58 \\
\hline 23 & 24 & 0,296 & 0,575 \\
\hline 24 & 26 & 0,295 & 0,56 \\
\hline 25 & 28 & 0,288 & 0,558 \\
\hline 26 & 30 & 0,288 & 0,522 \\
\hline 27 & 32 & 0,275 & 0,51 \\
\hline 28 & 34 & 0,264 & 0,509 \\
\hline 29 & 36 & 0,261 & 0,4743 \\
\hline 30 & 38 & 0,259 & 0,474 \\
\hline
\end{tabular}

\subsection{Tanks with variation in liquid's height :}

In this part, a container having a height of $10 \mathrm{~m}$ and a radius of $10 \mathrm{~m}$ was selected. The liquid level was changed each time while visualizing the variation of the MSWH's values. The results found are shown in Table 3:

Table 6. Results for the 3rd Part

\begin{tabular}{|c|c|c|c|}
\hline \multicolumn{4}{|c|}{ Part III } \\
\hline $\mathrm{n}$ & $\mathrm{H}(\mathrm{m})$ & $\begin{array}{c}\text { MSWH } \\
\text { ANSYS }(\mathrm{m})\end{array}$ & $\begin{array}{c}\text { MSWH EC8 } \\
(\mathrm{m})\end{array}$ \\
\hline 31 & 2,5 & 0,243 & 0,63 \\
\hline 32 & 3 & 0,255 & 0,63 \\
\hline 33 & 3,5 & 0,263 & 0,672 \\
\hline 34 & 4 & 0,269 & 0,714 \\
\hline 35 & 4,5 & 0,274 & 0,756 \\
\hline 36 & 5 & 0,294 & 0,808 \\
\hline 37 & 5,5 & 0,287 & 0,839 \\
\hline 38 & 6 & 0,292 & 0,86 \\
\hline 39 & 6,5 & 0,309 & 0,845 \\
\hline 40 & 7 & 0,323 & 0,84 \\
\hline 41 & 7,5 & 0,339 & 0,814 \\
\hline 42 & 8 & 0,326 & 0,809 \\
\hline 43 & 8,5 & 0,317 & 0,804 \\
\hline 44 & 9 & 0,315 & 0,798 \\
\hline 45 & 9,5 & 0,314 & 0,798 \\
\hline
\end{tabular}

\section{Conclusion}

In this work, we studied the effects of different geometrical properties of metal cylindrical tanks on maximum heights of sloshing waves occurring during a possible excitation in the base. At first, the accuracy of the finite element method has been validated, then the tanks were modelled and subsequently analyzed. the conclusions to be drawn from this study are summarized in the following points: 


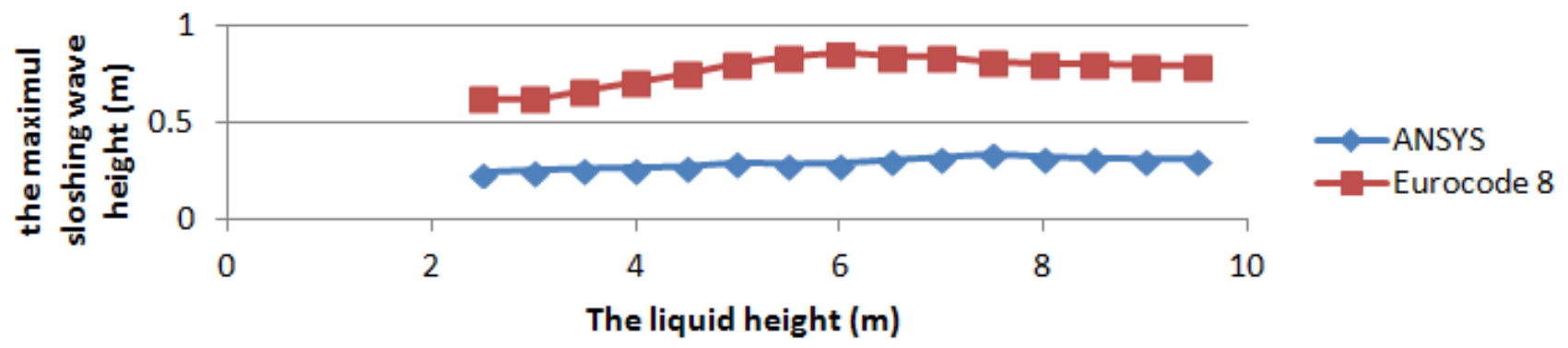

Figure 8. The MSWH's evolution versus the Liquid's Height.

-By varying the height only, it was observed that at the beginning the height of sloshing increase with increasing the height but after reaching a critical value, the values of the wave's height decrease, this decreasing is due to increasing of the flexibility of the tank because of sloshing.

From tanks analyzed with change of the radius only, it was observed that the maximum height of sloshing wave decrease with increasing the radius : indeed for the the same height, a tank having a larger radius is more rigid that a further having a smaller diameter .

For analysis where the liquid's height is varied, it was seen that the maximum height of the sloshing wave increases by increasing the height of the liquid .But after a critical value, the values of the MSWH decrease as the liquid-shell syste becomes more flexible. So there is a point to wherein the security of the tanks can be ensured.

\section{Recommendations}

From the evolution of the maximum wave sloshing values based on the heights of the tank and their radius, we can see that the critical values -where the waves are maximals- are for tanks having radius lower than their heights.

From the evolution of the maximum values waves sloshing based on liquid heights, we can see that there is a gap for the liquid height between $0.5 \mathrm{H}$ and 0.7 Hwhere the waves values are critical.

In the light of the results that either Eurocode 8 or digital experimentation upon the Ansys software, we recommend performing cylindrical metallic tanks for storage of small heights and large diameters, In that case the maximum heights of sloshing waves are most optimistic.

\section{References}

1. ANSYS, ICEM CFD, 11.0 User's Manual, ANSYS (2009).

2. R.C. Burros, R.F. Alves, WIT Transactions on the Built Environment, 57, 733-743 (2001).

3. Standard, British. Eurocode 8: Design of structures for earthquake resistance (2005).

4. D. Goulmot,Nouvelles méthodes numériques pour l'analyse sismique des réservoirs de liquide (2012).

5. M. Gradinscak, $\mathrm{PhD}$ dissertation, Victoria University Melbourne, Australia (2009).

6. ASCE, Technical Council on Lifeline Earthquake Engineering, New York (1984).

7. M.A. Haroun,G.W. Housner, ASCE, Journal of technical councils, 107, 1,191-207 (1981).

8. E.J. Hopfinger, V.Baumbach,EDP Sciences,Progress in Propulsion Physics, 1, 279-292 (2009).

9. G.W. Housner, Bulletin of the Seismological Society of America, 53, 2, 381-387 (1963).

10. J. B. Frandsen, Journal of Computational Physics, 196, 1, 53-87 (2004).

11. O.R. Jaiswal, S. Kulkarni, P. Pathak,Proceedings of the 14th World Conference on Earthquake Engineering, Beijing China, 12-17, October (2008).

12. H. Kazem, S. Mehrpouya, Journal of Structural Engineering and Geo-Techniques, 2, 1, 55-59 (2012).

13. R. Livaoglu,Soil dynamics and Earthquake Engineering,28, 2, 132-146 (2008).

14. M. J. N. Priestley, et al. Recommendations of a Study Group of the New Zealand National Society for Earthquake Engineering, 17 (1986).

15. A.N. Oskouei, E.N. Naghani,Journal of current research in Science, 2 , 5, 664-672 (2014).

16. R.S. Wozniak, W.W. Mitchell, APIRefining Department 43rd Midyear Meeting, Toronto, Canada (1978). 